\title{
ilerletme genioplastisinde kullanılan 5 farklı fiksasyon sisteminin stabilite ve stres dağııımlarının sonlu elemanlar analizi ile değerlendirilmesi
}

\author{
Ahmet Aktı(0000-0002-3447-0065) ${ }^{\alpha}$, Abdullah Kalaycı(0000-0001-5060-8901) ${ }^{\alpha}$
}

Selcuk Dent J, 2020; 7: 364-372 (Doi: 10.15311/selcukdentj.735291)

Başvuru Tarihi: 11 Haziran 2020 Yayına Kabul Tarihi: 12 Ağustos 2020

\section{öz}

Ilerletme genioplastisinde kullanılan 5 farklı fiksasyon sisteminin stabilite ve stres dağılımlarının sonlu elemanlar analizi ile değerlendirilmesi

Amaç: Bu genioplasti çalışmasının amacı; segmentlerinin fiksasyonunda kullanılan titanyum monokortikal miniplak ve bikortikal vida sistemlerinin deplasman miktarı, kemikte oluşturduğu asal stresler ile plak ve vidalarda oluşan von-mises stres dağııımlarının sonlu elemanlar analizi ile karşılaştırılmasıdır.

Gereç ve Yöntemler: Çalışmamızda alt çene ucunda genioplasti osteotomisi yapılarak distal fragman anteriora doğru $5 \mathrm{~mm}$ ilerletilmiştir. Fiksasyon olarak tek genioplasti plağı, 2 adet düz plak, 3 adet düz plak, 2 adet bikortikal vida ve 3 adet bikortikal vida fiksasyon modellerinin kullanıldığı 5 farklı modelde, alt segmente linguale doğru horizontal yönde 80 N' luk kuvvet uygulanarak ortaya çıkan deplasman ve stres değerleri sonlu elemanlar analizi ile değerlendirilmiştir.

Bulgular: En az deplasman üç adet titanyum bikortikal vida ile yapılan fiksasyon modelinde izlenirken, en fazla deplasman tek genioplasti plağı fiksasyon modelinde izlenmiștir. Materyallerde en az von-mises stres üç adet titanyum bikortikal vida ile yapılan fiksasyon modelinde, en fazla von-mises stres tek genioplasti plağı fiksasyon modelinde izlenmiştir. Kemikte en fazla gerilme stresi (Pmax) üç adet düz plak fiksasyon modelinde izlenirken en az gerilme stresi plak kullanılan fiksasyon modellerinde izlenmiştir. Kemikte en fazla sıkışma stresi (Pmin) iki adet bikortikal vida fiksasyon modelinde izlenirken en az sıkışma stresi iki ve üç adet düz plak fiksasyon modellerinde izlenmiştir.

Sonuç: Bikortikal vida grupları, deplasman ve von-mises gerilme stresleri açısından daha iyi sonuç vermekle birlikte, plak grupları gerilme ve sıkışma stresleri açısından daha elverișli bulunmuştur. Tüm bunlarla birlikte sonuçlar tüm gruplar için fizyolojik sınırlar içerisindedir.

\section{ANAHTAR KELIMELER}

Fiksasyon, genioplasti, sonlu eleman analizi

Ortognatik cerrahi, yüz kemikleri olan maksilla, mandibula ve dentoalveolar segmentlerle ilgili konjenital veya kazanılmış deformitelerin tedavi edildiği cerrahi yöntemdir. Çene ucundaki uyumsuzlukların düzeltilmesi amacıyla uygulanan ortognatik cerrahi prosedürü ise genioplastidir. ${ }^{1}$ Bir diğer adıyla inferior border osteotomisi olarak da adlandırılan genioplasti; mandibulanın anterioru ve gövdesindeki anomalilerin düzeltilmesi amacıyla, mandibulanın vertikal, transvers

\section{ABSTRACT}

Evaluation of stability and stress distributions of 5 different fixation systems used in advancement genioplasty by finite element analysis

Background: The aim of this genioplasty study is the comparison of titanium monocortical miniplate and bicortical screw fixation systems in terms of displacement, primary stresses and von-mises stress by finite element analysis.

Methods: In our study, genioplasty osteotomy was performed and the fragment was placed $5 \mathrm{~mm}$ anterior. In 5 different models using single genioplasty plate, 2 flat plates, 3 flat plates, 2 bicortical screws and 3 bicortical screw fixation models as fixation, $80 \mathrm{~N}$ force was applied to the distal segment in the horizontal direction. The displacement and stress values were evaluated by finite element analysis.

Results: The shortest displacement was observed in the three titanium bicortical screws system, while the longest displacement was observed in the single genioplasty plate system. The lowest and highest von-mises stress was seen in three titanium bicortical screw system and single genioplasty plate, respectively. The maximum von-mises stress was observed in three flat plate fixation system, while the minimum von-mises was observed in plate fixation system. The maximum compression bone stress was recorded in two bicortical screw system, the minimum compression bone stress was recorded in two and three flat plate systems.

Conclusion: Although bicortical screw groups give better results in terms of displacement and von-mises stress stresses, plate groups were found more favorable in terms of stress and compression stresses. However, the results are within physiological limits for all groups.

\section{KEYWORDS}

Fixation, genioplasty, finite element analysis

boyutlardaki formunun değiştirilmesi temeline dayanmaktadır. ${ }^{2,3}$

Çene, yüz şeklinin ve simetrisinin uyumunda estetik olarak belirleyici bir rol oynamaktadır. Mandibular ilerletme düşünüldüğünde, çene ucunun şeklinin de tedavi planlamasının bir parçası olarak değerlendirilmesi gerekmektedir. Çene estetiğini, çenenin vertikal boyutu, alt dudak uzunluğu, alt dudak vermillion görünürlüğü, labiomental kıvrım,

\footnotetext{
${ }^{\alpha}$ Selçuk Üniversitesi Diş Hekimliği Fakültesi Ağız, Diş ve Çene Cerrahisi Anabilim Dalı, Konya
} 
dudak-çene-boğaz açısı, çene kurvatürü, pogonyonun konumu gibi faktörler belirler. Bu sebeple yüz asimetrisi ve yüz estetiğini düzeltme amacıyla uygulanan tekniklere genioplasti de sıklıkla eşlik etmektedir.4,5

Genioplasti operasyonlarında ilerletilmiş genial segmentin stabilizasyonu amacıyla önceleri daha çok tel osteosentezi tekniği kullanılmıştır. ${ }^{6}$ Ancak tel ile fiksasyon tekniğinin yeterince rijit olmaması, relapsların fazla olması gibi istenmeyen sonuçları nedeniyle yeni arayışlara girilerek, uzun yıllardır da güvenle kullanılan metal plaklar, vida sistemleri ve bunların farklı kombinasyonlarını da içeren rijit fiksasyon teknikleri uygulanmaya başlanmıştır. ${ }^{7}$ Ancak onlarca yıldır tedavilerde standart haline gelmelerine rağmen, bu sistemlerde kullanılan materyaller, aşırı kuvvet yüklenmesi, plak kemik uyumundaki başarısızlıklar, materyallerin tasarımı, imalatı ve saflığındaki problemler gibi hem cerrahi hem de materyalle ilgili birçok faktörden dolayı başarısız olabilmektedirler. ${ }^{8,9,10}$

Diş hekimliğinde kullanılan materyallerin biyomekanik özelliklerinin değerlendirilmesi ve dental yapılarda oluşan gerilmelerin belirlenmesi amacıyla, bu yapıların stres analiz ölçümlerinin yapılması son yıllarda oldukça yaygınlaşmıştır. Canlı doku ve organların, kuvvetler karşısında nasıl bir davranış sergilediğini tespit etmek ve gerilme analizi yapmak zor, pahalı, riskli ve bazen de imkansız olabilmektedir. ${ }^{11} \mathrm{Bu}$ sebeple stres analiz çalışmalarının canlı dokuları temsil eden modeller üzerinde yapılması gerekebilmektedir. Bir cismin üzerine gelen kuvvetlerin yoğunlaştığı bölgelerin görülmesi ve o cismin kuvvetler karşısında daha güçlü ve dayanıklı olabilmesi için tasarım veya kombinasyonunun nasıl olması gerektiğini önceden tespit etmek amacıyla çeşitli stres analiz yöntemleri kullanılmaktadır. Bu amaçla diş hekimliği alanında en çok kullanılan analizlerden biri sonlu eleman analiz tekniğidir. Parçadan bütüne gitme prensibine dayanan teknik, biyomekanik sistemin gerçeğe uygun matematiksel modelinin elde edilmesi ile bilgisayar ortamında bu modelin çözümlenmesi esasına dayanmaktadır. Yapılan analizde kemikteki asal stresler sıkışma (Pmin) ve gerilme stresleri (Pmax) olarak, materyalde ise von-mises stresleri olarak değerlendirilmektedir.

$\mathrm{Bu}$ çalışmada, ilerletme genioplastisi fiksasyonunda kullanılan farklı sayıda ve farklı konfigürasyonlardaki plak ve vida sistemlerinin; deplasman miktarlarının, kemikte oluşturdukları asal streslerin ve materyallerde oluşan von-mises stres dağılımlarının sonlu eleman analizi ile değerlendirilmesi ve birbirleriyle karşılaştırılması amaçlanmıştır.

\section{GEREÇ VE YÖNTEM}

Alt çenenin modellemesi için arşivde bulunan 20 yaşındaki bir hastanın 3M Iluma CBCT (ILUMA, Orthocad, BT, 3M Imtec, Oklahoma, ABD) cihazı kullanılarak çekilmiş tomografi verileri kullanılmıştır. Tomografide elde edilen verilerle ilk olarak, 3DDoctor (Able Software Corp. MA, ABD) yazılımında "Interactive Segmentation" yöntemi ile "Hounsfield Değerleri" ne bakılarak kemik dokusunun ayrıştırıma işlemi gerçekleştirilmiştir. Daha sonra, "3D Complex Render" yöntemi ile 3 boyutlu model elde edilip 3D-Doctor yazılımı ile dışa aktarılmıştır. Kemik dokusundan offset yöntemi ile spongioz kemik elde edilmiştir. Hazırlanan mandibula modelinde mental foramen, dişlerin kök uçları ve mandibuler kanal gibi önemli anatomik yapılar korunacak şekilde horizontal düzleme yakın bir açılla ilerletme genioplasti osteotomisi simüle edilmiştir. Osteotominin ardından ayrılan distal fragman herhangi bir rotasyonel harekette bulunulmadan, $5 \mathrm{~mm}$ anteriora ilerletilmiştir.

Titanyum plak ve vidalar AutoCAD (Autodesk Inc., PA, ABD) programı ile 3 boyutlu olarak modellenmiştir. Titanyum materyal programa tanıtılarak aynı boyutlarda modelleme işlemleri tamamlanmıştır. Rhinoceros yazılımında plak ve vidalar ile kemik doku arasında uyumlandırma yapılmış ve materyaller arasındaki temasların gerçeğe en yakın olması sağlanarak kuvvet aktarımı gerçekleştirilmiştir.

Modeller, Rhinoceros yazılımı ile geometrik olarak oluşturulmasının ardından Algor Fempro (Algor Inc., ABD) yazılımına aktarılmıştır. Mandibula modellerinin ve fiksasyon sistemlerinin hangi materyalden olduğu, elastiklik modülleri ve poisson oranları yazılıma tanıtılmıştır (Tablo 1). ${ }^{12}$ Daha sonra da Algor yazılımında analizlerin yapılabilmesi için üç boyutlu ağ yapısı (mesh) oluşturulmuştur. Ayrıca tüm materyaller homojen, izotropik ve lineer elastik olarak kabul edilmişlerdir.

Tablo 1.

\section{Materyallerin mekanik özellikleri ${ }^{10}$}

\begin{tabular}{|lcc|}
\hline & Young Modülü (MPa) & Poisson Oranı \\
\hline Kortikal kemik & 13700 & 0.3 \\
\hline Spongiöz kemik & 1370 & 0.3 \\
\hline Titanyum & 110000 & 0.35 \\
\hline
\end{tabular}

Araştırmada diş kökleri ve mental foramen gibi önemli anatomik yapılar korunacak şekilde gerçeğe en yakın ilerletme genioplastisi osteotomisi simüle edilmiş ve distal fragman 5 $\mathrm{mm}$ ilerletilmiştir. Ardından $5 \mathrm{~mm}$ ilerletilen distal segmente beş farklı fiksasyon modeli uygulanmıştır (Şekil 1).

a) Model 1: 6 delikli tek genioplasti plağı modeli

b) Model 2: 2 adet 2 şer delikli düz plak modeli

c) Model 3: 3 adet 2 şer delikli düz plak modeli

d) Model 4: 2 adet bikortikal vida modeli

e) Model 5: 3 adet bikortikal vida modeli 

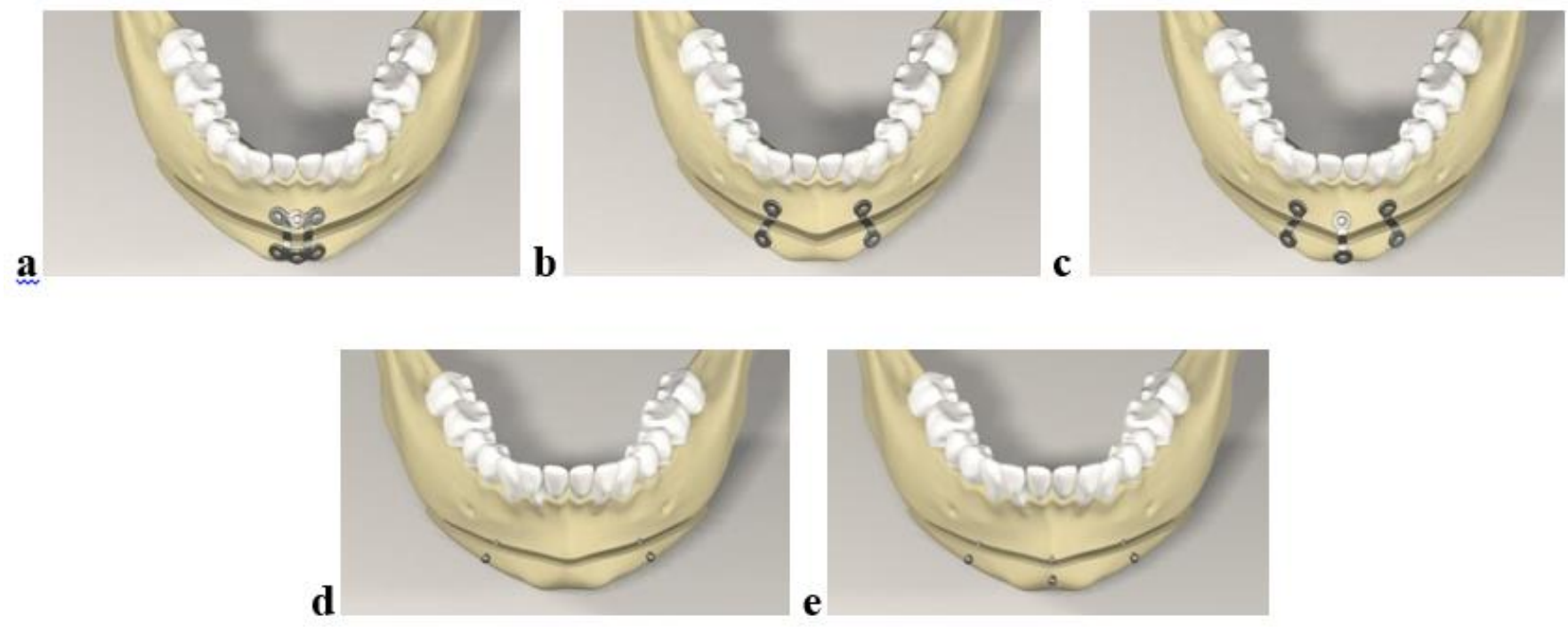

Şekil 1.

3D Doctor yazılımı ile bilgisayar ortamında 5mm'lik ilerletme genioplastisi uygulanıp analize hazır hale getirilmiş modeller

Fiksasyon modellerinde kullanılan plakların kalınlığı 0.6 mm'dir, plaklara yerleştirilen vidalar ise 2.0 fiksasyon sistemine aittir ve boyları $7 \mathrm{~mm}$ 'dir. Sadece vida fiksasyonu gruplarında kullanılan vidalar da 2.0 fiksasyon sistemine ait ve boyları $15 \mathrm{~mm}$ 'dir.

Mevcut modellere de suprahyoid kasları taklit edecek şekilde horizontal olarak orta hattın sağından ve solundan $40 \mathrm{~N}$ olmak üzere toplamda $80 \mathrm{~N}$ kuvvet uygulanmıştır. Distal fragmanda oluşan deplasman değerleri ile fiksasyon materyallerinde oluşan stres değerleri ve stres dağılımlarının analizleri yapılmıştır. Araştırma üç boyutlu sonlu elemanlar stres analizi yöntemi ile statik lineer analiz yapılarak gerçekleştirildiği için istatistiksel değerlendirme yapılamamıştır.

Ağ yapısının oluşturulması işleminde, modeller mümkün olabildiğince 8 düğüm noktalı (brick tipi) elemanlardan oluşturulmuştur. Modellerdeki yapıların merkezine yakın bölgelerde gerektiğinde yapının detaylarının daha iyi verilebilmesi amacıyla daha az düğüm noktalı elemanlar da kullanılmıştır. Bu modelleme tekniği sayesinde hesaplamayı kolaylaştırmak üzere mümkün olan en yüksek düğüm noktalı elemanlar ile en yüksek kalitede ağ yapısı oluşturulmaya çalışılmıştır (Tablo 2). Çene modellerinde bulunan ve analiz işlemini zorlaştıran dik ve dar bölgeler çizgisel elemanlardan arındırılarak düzenli hale getirilmiştir.

Tablo 2.

\section{Analizde kullanılan modellerin düğüm ve eleman sayıları}

\begin{tabular}{ll} 
& Düğüm ve Eleman Sayıları \\
\hline Model 01 & Düğüm sayısı $=147741$ Element sayısı $=662364$ \\
\hline Model 02 & Düğüm sayııı $=124674$ Element sayısı $=548039$ \\
\hline Model 03 & Düğüm sayıII $=157563$ Element sayısı $=699551$ \\
\hline Model 04 & Düğüm sayısı $=80337$ Element sayısı $=346181$ \\
\hline Model 05 & Düğüm sayısı $=88154$ Element sayısı $=387179$
\end{tabular}

\section{BULGULAR}

Çalışma modellerinde fiksasyon materyallerinde oluşan stresler von-mises stresler şeklinde analiz edildi (Şekil 2). Kemikte oluşan stres ise hem distal hem de proksimal fragmanlarda baskı ve gerilme kuvvetlerinin analizi için minimum asal stresler ve maksimum asal stresler şeklinde analiz edildi (Şekil 3). Deplasman değerleri sonuçları için de ön-arka yönü gösteren $Y$ komponentinde oluşan deplasman miktarları pogonyon noktasının hareketi referans alınarak değerlendirildi (Şekil 4).

Plakların von-mises stresleri değerlendirildiğinde sirasiyla Model 1'de $80.25 \mathrm{~N} / \mathrm{mm}^{2}$, Model 2'de 75.31 $\mathrm{N} / \mathrm{mm}^{2}$ ve Model 3'de $71.82 \mathrm{~N} / \mathrm{mm}^{2}$ stres değerleri görülmektedir. Çok belirgin bir değişiklik olmamakla birlikte plak sayısının artmasıyla birlikte plaklarda oluşan stresin azaldığı görülmektedir. Vidalarda biriken max stresler değerlendirildiğinde ise en yüksek stres Model 1 'de $84.11 \mathrm{~N} / \mathrm{mm}^{2}$, en düşük stres de Model 5'de $26.53 \mathrm{~N} / \mathrm{mm}^{2}$ olarak görülmektedir. Plak kullanılmayıp sadece vida ile fiksasyon uygulanan Model 4 ve Model 5 gruplarında vidalarda daha az stres birikmiştir. Aynı zamanda 2 plaklı ile 3 plaklı gruplar kıyaslandığında ortaya gelen 3 . plak yanlardaki plaklarda ve vidalarda stres miktarını azaltmıştır. Aynı durum 2 vidalı ve 3 vidalı Model 4 ve Model 5 arasında da geçerlidir. Ortaya gelen 3 . vida yanlardaki vidalardaki stres miktarını benzer şekilde azaltmıştır. Ancak hem Model 3 hem de Model 5'de ortaya yerleştirilen plaktaki vidalarda stres yanlarında bulunan vidalara göre daha yüksek çıkmıştır. Gruplardaki fiksasyon sistemlerinde oluşan toplam von-mises stres miktarları değerlendirildiğinde ise en yüksek stres Model 1'de $164.36 \mathrm{~N} / \mathrm{mm}^{2}$, en düşük stres ise Model 5'de 26.53 $\mathrm{N} / \mathrm{mm}^{2}$ şeklindedir (Tablo 3). 


\section{Model 1}
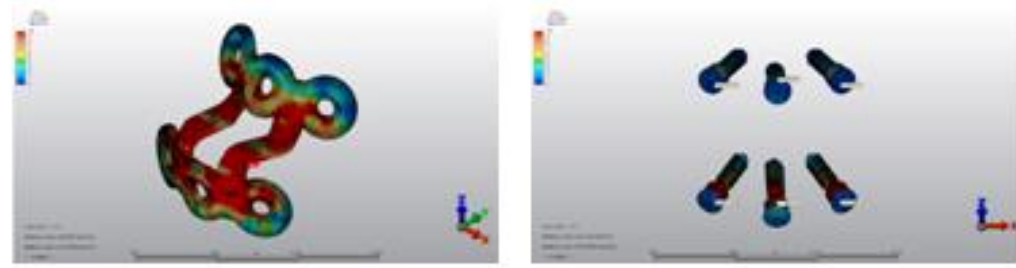

Model 2
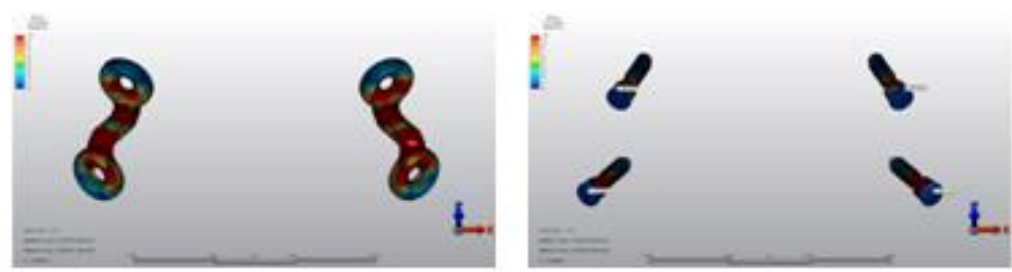

Model 3
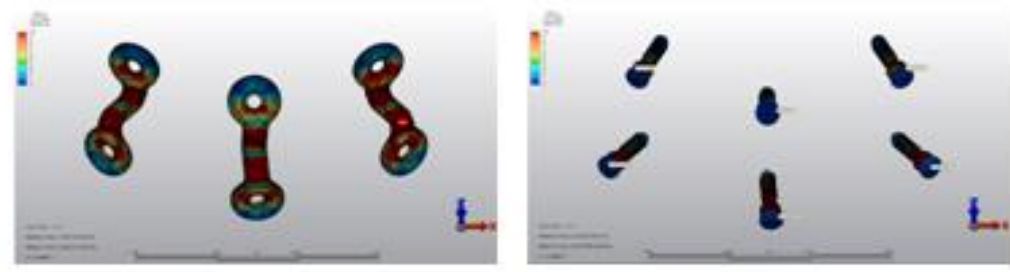

Model 4

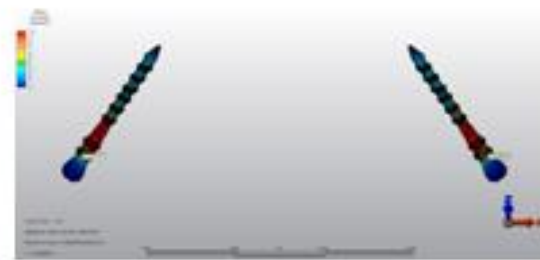

Model 5

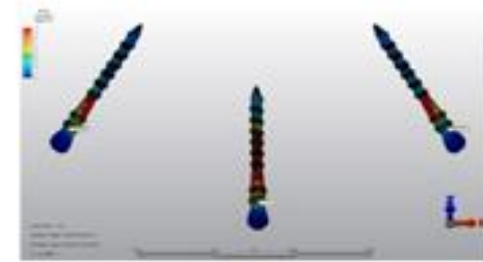

Şekil 2.

Plak ve vidaların von-mises stres dağılımları
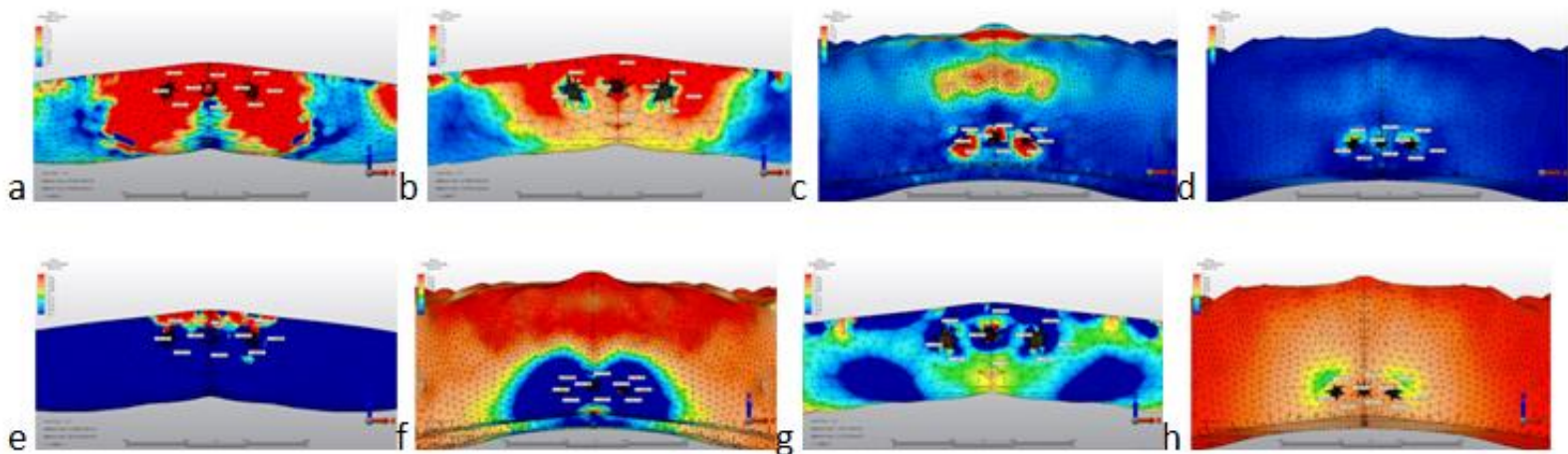

Sekil 3

Maksimum ve minimum asal stres analiz örnekleri

a) distal kortikal kemik pmax, b) distal trabeküler kemik pmax, c) proksimal kortikal kemik pmax, d) proksimal trabeküler kemik pmax, e) distal kortikal kemik pmin, f) distal trabeküler kemik pmin, g) proksimal kortikal kemik pmin, h) proksimal trabeküler kemik pmin 


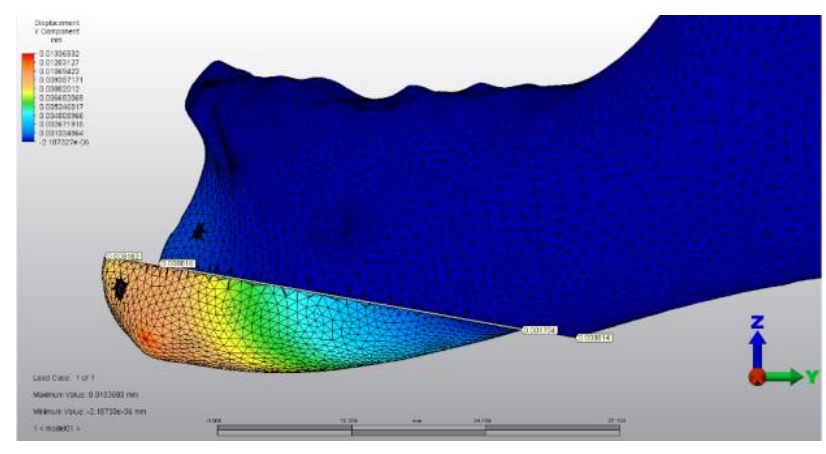

Şekil 4.

Sonlu eleman analizi deplasman miktarı örneği

Tablo 3.

Plak ve vidaların toplam von-mises stres değerleri

\begin{tabular}{|lc|}
\hline Model No & Plak ve vidalardaki toplam von-mises stres $\left(\mathbf{N} / \mathbf{m m}^{2}\right)$ \\
\hline Model 1 & 164,36 \\
\hline Model 2 & 145,33 \\
\hline Model 3 & 139,21 \\
\hline Model 4 & 52,37 \\
\hline Model 5 & 26,53 \\
\hline
\end{tabular}

Kemik dokularda oluşan maksimum asal stresler yani gerilme kuvvetleri değerlendirildiğinde, 5 model içerisinde distal segmentte kortikal kemikte en yüksek max asal stres değeri Model 3'de $6.9 \mathrm{~N} / \mathrm{mm}^{2}$ olarak izlenmiştir. Distal segment trabeküler kemikte ise en yüksek max asal stres değeri Model 5'de 0.72 $\mathrm{N} / \mathrm{mm}^{2}$ olarak izlenmiştir. Genel olarak bakılırsa distal segmentte en yüksek max asal stresin Model 3'de kortikal kemikte olduğu görülmektedir.

Proksimal segmentte kortikal kemikte en yüksek max asal stres değeri Model 4'de 2.40 N/mm² olarak izlenmiştir. Proksimal segment trabeküler kemikte ise en yüksek max asal stres değeri Model 5'de 0.07 $\mathrm{N} / \mathrm{mm}^{2}$ olarak izlenmiştir. Genel olarak bakılırsa proksimal segmentte en yüksek max asal stresin Model 4'de olduğu görülmektedir (Tablo 4).

Tablo 4.

\section{Maksimum asal stresler $\left(\mathrm{N} / \mathrm{mm}^{2}\right)$}

\begin{tabular}{|lcccc|}
\hline & $\begin{array}{c}\text { Distal } \\
\text { segment } \\
\text { kortikal } \\
\text { kemik }\end{array}$ & $\begin{array}{c}\text { Distal } \\
\text { segment } \\
\text { trabeküler } \\
\text { kemik }\end{array}$ & $\begin{array}{c}\text { Proksimal } \\
\text { segment } \\
\text { kortikal } \\
\text { kemik }\end{array}$ & $\begin{array}{c}\text { Proksimal } \\
\text { segment } \\
\text { trabeküler } \\
\text { kemik }\end{array}$ \\
\hline Model 1 & 6,24 & 0,37 & 0,48 & 0,02 \\
\hline Model 2 & 1,14 & 0,18 & 0,13 & 0,02 \\
\hline Model 3 & 6,9 & 0,67 & 0,09 & 0,02 \\
\hline Model 4 & 1,02 & 0,52 & 2,4 & 0,06 \\
\hline Model 5 & 5,95 & 0,72 & 0,87 & 0,07 \\
\hline
\end{tabular}

Kemik dokularda oluşan minimum asal stresler yani sıkışma kuvvetleri değerlendirildiğinde, 5 model içerisinde distal segmentte kortikal kemikte en yüksek min asal stres değeri Model 2'de - 1.99 N/mm² olarak izlenmiştir. Distal segment trabeküler kemikte ise en yüksek min asal stres değeri yani en yüksek sıkışma kuvveti Model 4'de -1.68 N/mm² olarak izlenmiştir. Genel olarak bakılırsa distal segmentte en yüksek min asal stres yani sıkışmanın Model 2'de olduğu görülmektedir.

Proksimal segmentte kortikal kemikte en yüksek min asal stres değeri Model 42de $-3.14 \mathrm{~N} / \mathrm{mm}^{2}$ olarak ölçülmüştür. Proksimal segment trabeküler kemikte en yüksek min asal stres değeri Model 4'de $-0.33 \mathrm{~N} / \mathrm{mm}^{2}$ olarak ölçülmüştür. Genel olarak bakılırsa proksimal segmentte en yüksek min asal stres yani sıkışmanın Model 4'de olduğu görülmektedir (Tablo 5).

Modellerdeki deplasman miktarının karşılaştırılmas amacıyla da pogonyon noktasının kuvvetin uygulandığı eksen olan $Y$ eksenindeki hareketi referans alındı. En çok deplasmanın Model 1'de, en az deplasmanın da Model 5'de olduğu görülmektedir (Tablo 6).

\section{Tablo 5}

\section{Minimum asal stresler $\left(\mathrm{N} / \mathrm{mm}^{2}\right)$}

\begin{tabular}{|lcccc|}
\hline & $\begin{array}{c}\text { Distal } \\
\text { segment } \\
\text { kortikal } \\
\text { kemik }\end{array}$ & $\begin{array}{c}\text { Distal } \\
\text { segment } \\
\text { trabeküler } \\
\text { kemik }\end{array}$ & $\begin{array}{c}\text { Proksimal } \\
\text { segment } \\
\text { kortikal } \\
\text { kemik }\end{array}$ & $\begin{array}{c}\text { Proksimal } \\
\text { segment } \\
\text { trabeküler } \\
\text { kemik }\end{array}$ \\
\hline Model 1 & $-0,8$ & $-0,28$ & $-2,17$ & $-0,12$ \\
\hline Model 2 & $-1,99$ & $-0,27$ & $-0,92$ & $-0,09$ \\
\hline Model 3 & $-1,86$ & $-1,1$ & $-0,76$ & $-0,09$ \\
\hline Model 4 & $-1,01$ & $-1,68$ & $-3,14$ & $-0,33$ \\
\hline Model 5 & $-0,96$ & $-0,76$ & $-1,74$ & $-0,23$ \\
\hline
\end{tabular}

Tablo 6.

\section{Deplasman miktarları ( $\mathrm{mm}$ )}

\begin{tabular}{|lc|}
\hline Deplasman miktarları & Y ekseni $(\mathbf{m m})$ \\
\hline Model 1 & 0,008 \\
\hline Model 2 & 0,006 \\
\hline Model 3 & 0,006 \\
\hline Model 4 & 0,006 \\
\hline Model 5 & 0,002 \\
\hline
\end{tabular}




\section{TARTIŞMA}

Genioplasti ile ayrlıp stabilize edilen segmentler, postoperatif dönemde diğer ortognatik cerrahi prosedürleri kadar yüksek kuvvetlere maruz kalmamaktadırlar. Bu nedenle genioplasti, relapsların daha az olduğu, güvenilir bir teknik olarak bilinmektedir. ${ }^{3,13}$ Ancak birbirinden ayrılmış segmentlerin başarıı iyileşebilmesi için de maksimum stabilizasyona intiyaç olduğu bir gerçektir. Literatürde, bu segmentlerin fiksasyonu için birçok teknik tanımlanmış ve farklı çalışmalar ile karşılaştııımışlardır. Polido ve ark., Shaughnessy ve ark., Shaik ve ark. çalışmalarında tel ve plak sistemini karşılaştırmışlar, Reyneke ve ark. tel ile vida sistemini karşılaştırmışlar, Ramos ve ark. çalışmalarında farklı plak sistemlerini karşılaştırmışlar, Lee ve ark. metal plaklarla rezorbe olan plak sistemlerini karşılaştırmışlar, Yurtyapan ve ark. metal ve rezorbe olabilen vida sistemlerini karşılatırmışlardır. ${ }^{6,12,13,14,17}$ Ancak literatürde plak ve vida sistemlerini aynı çalışma içerisinde karşılaştıran çalışma sayısı yetersizdir. Bu amaçla, rijit fiksasyon ile stabilizasyonun uygulandığı genioplasti prosedürlerinde araştırılan gruplar arasında en ideal fiksasyon tekniğini bulabilmek için farklı sayıda ve konfigürasyondaki titanyum plak ve vida fiksasyonlarının uygulandığı 5 ayrı analiz yapmış ve değerlendirmiş bulunmaktayız.

Çalışmada ilerletme miktarının $5 \mathrm{~mm}$ olarak belirlenmesinin nedeni, rutinde $5 \mathrm{~mm}$ veya yakın miktarlardaki ilerletmelerin daha sıklıkla uygulanıyor olmasıdır. Ayrıca literatürde ilerletme miktarının $5 \mathrm{~mm}$ üzerine çıkması ile relaps oranlarının da arttığı bildirilmektedir. ${ }^{6,15,16}$ Lee ve ark. metal plaklarla rezorbe olan plakların ilerletme genioplastisi sonrası stabilizasyonunu karşılaştırdıkları çalışmada, metal plaklarda $4.33 \mathrm{~mm}$ ilerletme sonrası $0.48 \mathrm{~mm}$ relapsla karşılaştıklarını bildirmişlerdir. ${ }^{15}$ Shaik ve ark. tel ile osteosentez tekniği kullandıkları semirijit fiksasyon grubu ile metal plak kullandıkları rijit fiksasyon gruplarının stabilizasyonunu karşılaştırmışlardır. Çalışmanın sonuçlarına bakıldığında semirijit fiksasyon grubunda $5.97 \mathrm{~mm}$ 'lik ilerletme yapılmış ve 1 yıl sonunda $1.62 \mathrm{~mm}$ relaps görülmüş, rijit fiksasyon grubunda da $4.81 \mathrm{~mm}$ ilerletme yapılmış ve $1 \mathrm{yıl}$ sonunda $0.2 \mathrm{~mm}$ relaps görülmüştür. ${ }^{6}$ Reyneke ve ark. yaptıkları benzer bir çalışmada tel kullanılarak yapılan semirijit fiksasyon tekniği ile vida kullanılarak yapılan rijit fiksasyonu, stabilizasyon açısından karşılaştırmışlar ve 6-10 aylık takiplerinde $5.8 \mathrm{~mm}$ ilerletme yaptıkları semirijit fiksasyon grubunda $0.5 \mathrm{~mm}, 6.3 \mathrm{~mm}$ ilerletme yaptıkları rijit fiksasyon grubunda ise $0.3 \mathrm{~mm}$ relaps meydana geldiğini bildirmişlerdir. ${ }^{16}$

Osteotomize edilmiş segmentler, kemik iyileşmesi döneminde suprahyoid kasların doğrudan geri çekim kuvvetlerine maruz kalmaktadır. ${ }^{12,17} \mathrm{Bu}$ sebeple çalışmamızda genioplasti operasyonu sonrası osteotomize edilen distal segmente suprahyoid kasların uyguladığı geri çekim kuvvetini simüle edecek şekilde horizontal olarak geriye doğru kuvvet uygulanmıştır. Uygulanan kuvvetler suprahyoid kasların maksimum gerginliğini değerlendiren çalışmalar esas alınarak belirlenmiştir. Farklı araştırmacılar yaptıkları çalışmalarda kasların gerginlik, uzunluk ve kesit alanlarına göre yaklaşık olarak maksimum kas gerginliklerini hesaplamışlardır. ${ }^{18,19}$ Çalışmamıza benzer bir şekilde Yurtyapan ve ark. alt çene ucu ilerletmesi yaptıkları çalışmalarında suprahyoid kasların geri çekim kuvveti olarak toplamda 100 N'luk bir geri çekim kuvveti simülasyonu yapmışlardır. ${ }^{17}$ Ramos ve ark. sonlu eleman analizi ile genioplastideki farklı plak fiksasyonlarını karşılaştırdıkları çalışmada 5 $\mathrm{N}$ oblik, $5 \mathrm{~N}$ da dik kuvvet uygulamışlar ancak bu kuvvetlerin ne amaçla uygulandığı konusunda açıklamada bulunmamışlardır. ${ }^{12} \mathrm{Bu}$ çalışmada mevcut araştırmalar dikkate alınarak, horizontal yönde suprahyoid kasları taklit edecek şekilde geri çekme kuvveti olarak sağdan $40 \mathrm{~N}$ ve soldan $40 \mathrm{~N}$ olmak üzere toplamda 80 N'luk bir kuvvet simülasyonu yapılmıştır.

Birçok araştırmacı, kemik modellerinin biyomekanik davranışlarını tanımlamada sonlu elemanlar analizinin gerçeğe uygun olduğunu bildirmiş ve bu yöntem ile mandibula örnekleri üzerindeki in vitro ölçümler arasında yüksek korelasyon bildirmişlerdir. ${ }^{20,21}$ Ancak sonlu eleman analizi modellemeleri materyal karakteristiklerine ilişkin çok fazla varsayım içermektedir ve bunlar normal klinik şartlardan biraz farklı olabilmektedirler. Örneğin, gerçekte kemik homojen ve izotropik olmamasına rağmen kemiğin gerçek özelliğini modellerde yansıtmanın güç olması sebebiyle ve kemiğin gerçek davranış özellikleri tam olarak bilinmediği için, birçok araştırmada olduğu gibi yaptığımız çalışmada da kemiğin homojen ve izotropik olduğu varsayılmıştır. ${ }^{22,23}$

Ortognatik cerrahi prosedürlerde olduğu gibi genioplastide de fiksasyon yöntemlerinden monokortikal plakların veya bikortikal vidaların hangisinin kullanılması gerektiği ile ilgili kesin bir ayrım yapılamamaktadır. Bildiğimiz kadarıyla, literatürde genioplastide bikortikal vida ve monokortikal plak tekniklerini karşılaştıran çalışma bulunmamaktadır. $\mathrm{Bu}$ nedenle farklı ortognatik cerrahi prosedürlerdeki fiksasyon çalışmaları değerlendirilmiştir. Al-Moraissi ve ark. yaptıkları metaanalizde bilateral sagital split osteotomisi ile mandibular ilerletme yapılan hastalarda iskeletsel stabilite sonuçlarına göre bikortikal vida ve monokortikal plak fiksasyon sistemlerini karşılaştırmışlar ve bikortikal vida fiksasyonunun monokortikal plak fiksasyonuna göre daha rijit ve daha az deformasyon gösterme eğiliminde olmasına rağmen aralarında istatistiksel olarak anlamlı bir fark olmadığını bildirmişlerdir. ${ }^{24}$ Yine aynı araştırmacı başka bir metaanalizde mandibular setback prosedürü için bilateral sagital split osteotomisi 
yapılan hastalarda bikortikal vida fiksasyonu ile monokortikal plak fiksasyonunu iskeletsel stabilite açısından karşılaştırmışlar ve bikortikal vida fiksasyonunun monokortikal plaktan daha iyi bir iskeletsel stabilite sağladığını ancak aralarında istatistiksel olarak anlamlı bir fark olmadığını bildirmişlerdir. ${ }^{25}$ Choi ve ark. 30 hasta üzerinde bilateral sagital split osteotomisi ile mandibular set back prosedürü uygulamışlar ve 15 hastada miniplak fiksasyonu ile intermaksiller fiksasyon, 15 hastada da intermaksiller fiksasyon uygulamaksızın 2 adet bikortikal vida fiksasyonu uygulamışlardır. Her iki grupta da 6 haftalık postoperatif dönemde stabilite açısından istatistiksel olarak anlamlı bir fark bulunamamıştır ancak bikortikal vida kullanımı ile intermaksiller fiksasyona gerek kalmayacağını belirtmişlerdir. ${ }^{26}$ Chung ve ark.'da yaptıkları retrospektif araştırmada bilateral sagital split osteotomisi ile mandibular set back prosedürü uygulanmış 60 hastada monokortikal plak ve bikortikal vida fiksasyon sistemlerini postoperatif stabilite açısından karşılaştırmışlar ve her iki sistemin de aralarında anlamlı bir fark olmadığını ve güvenle kullanılabileceklerini belirtmişlerdir. ${ }^{27}$ Benzer şekilde Anucul ve ark.'da sagital split osteotomisinde monokortikal plak ve bikortikal vida fiksasyonların karşılaştırmışlar ve bikortikal vidanın deformasyona daha dirençli olduğunu bildirmişlerdir. ${ }^{28} \mathrm{Bu}$ bulgular bizim çalışmamamızla da paralellik göstermektedir. Bikortikal vida fiksasyonu uygulanan gruplarda plak uygulanan gruplara göre hem deplasman değerleri daha az bulunmuş, hem de toplam stres miktarının daha az olduğu sonucuna varılmıştır.

Sugiura ve ark.'da birçok çalışmada olduğu gibi yüksek stresli bölgelerle kemik rezorpsiyonu arasında doğrudan bir ilişki olduğunu ortaya koymuşlar; özellikle kemik rezorpsiyonunun ve buna bağlı olarak vidaların gevşemesinin postoperatif aşamada yüksek stresler ile ilişkili olduğunu bildirmişlerdir. Yaklaşık -40 MPa'lık basınç gerilmesinin kemik için fizyolojik olduğu ve kemik rezorpsiyonu için kritik eşik değerinin -50 Mpa civarında olduğunu bildirmişlerdir. ${ }^{29} \mathrm{Bu}$ çalışmadaki analizlerde de modellerin hiçbirinde $50 \mathrm{MPa}$ sınırına ulaşımadığı görülmektedir. Bütün modeller içinde en fazla gerilme stresinin, 3 plak kullanılan Model 3'de distal segmentteki kortikal kemik bölgesinde olduğu görülmüştür (6.9 Mpa). $\mathrm{Bu}$ değer kemik maksimum dayanım kuvvetini aşmamaktadır. En büyük sıkışma stresi ise proksimal segmentte 2 adet bikortikal vida ile fiksasyon sağlanan Model 4'de proksimal segmentteki kortikal kemikte oluşmuştur(-3.14 Mpa). Bu değer de -50 Mpa'nın altında olduğu için fizyolojik sınırlar içerisindedir ve herhangi bir rezorpsiyon beklenmemektedir. Diğer modellerde de gerilme streslerinin ve sıkışma streslerinin kemik maksimum dayanım kuvvetini ve rezorpsiyon sınırını aşmadığı bu nedenle de gruplarda herhangi bir rezorpsiyon ya da deformasyona neden olabilecek aşırı stresin oluşmadığı gözlenmiştir. Hem gerilme stresleri hem de sıkışma stresleri açısından modeller birbirleriyle kıyaslandığında ise bariz bir farktan bahsedilememektedir.
Analiz sonuçlarına göre deplasman miktarları ilk grupta $0.008 \mathrm{~mm}, 2,3$,ve 4 . gruplarda $0.006 \mathrm{~mm}$ son grupta da $0.002 \mathrm{~mm}$ olarak ölçülmüştür. Ganesh ve ark. yaptıkları hayvan çalışmasında istenilen kemik iyileşmesinin olabilmesi için fragmanlar arası deplasmanın maksimum 0.5 mm olması gerektiğini vurgulamaktadırlar. ${ }^{30}$ Çalışmamızdaki grupların hiçbirinde bu fizyolojik sınır aşılmamış olup gruplardaki fiksasyon sistemlerinin bu açıdan da güvenli olduğu düşünülmektedir.

\section{SONUÇ}

Elde edilen sonuçlara göre, titanyum monokortikal plak kullanılan gruplarda ortada tek bir genioplasti plağı kullanmaktansa 2 veya 3 adet monokortikal düz plak kullanılması stres ve deplasman değerleri açısından daha uygun görülmüştür. Yine elde edilen sonuçlara göre bikortikal titanyum vida kullanılan grupların titanyum plak kullanılan gruplara göre stabilite ve deplasman değerlerinin daha iyi olduğu görülmüştür. Bu nedenle, bu çalışma sınırları içinde (5 mm'yi geçmeyen ilerletme genioplastisi) bikortikal titanyum vida kullanımını hastanın dışarıdan daha az hissedecek olması ve yeterli dayanıklılığı göstermesi nedeniyle titanyum plak kullanımına tercih edebileceğimizi düşünmekteyiz. Özellikle 2 titanyum bikortikal vida kullanılan grupta sonuçlar yaklaşık olarak 3 titanyum bikortikal vida kullanılan grupla benzer olduğundan; operasyon süresi, sağlam dokuların daha az zarar görmesi, olabildiğince konservatif yaklaşabilmek ve daha düşük maliyet amacıyla 2 titanyum bikortikal vida kullanımı önerilebilir.

Elde edilen sonuçların hepsi fizyolojik sınırlar içerisindedir. Bu nedenle çalıştığımız her grup için genioplasti fiksasyonunda güvenle kullanılabilir yorumunu yapabilmekteyiz. Ancak konuyla ilgili daha ayrıntılı, ilave çalışmalara ihtiyaç duyulmaktadır 


\section{KAYNAKLAR}

1. Chow B, Lau A. The planning of orthognathic surgerythe digital era. The Hong Kong Medical Diary 2009; 14(6): 11-4.

2. Precious DS, Cardoso AB, Cardoso MCA, Doucet JC. Cost comparison of genioplasty: when indicated, wire osteosynthesis is more cost effective than plate and screw fixation. Oral and maxillofacial surgery. 2014; 18(4): 439-44.

3. Proffit WR, White RP. and D.M. Sarver. Contemporary treatment of dentofacial deformity. Mosby, 2003.

4. Brons, R. Facial harmony: standards for orthognathic surgery and orthodontics. 1998: Quintessence Publishing Company Limited.

5. Reyneke, J. Essentials of orthognathic surgery, 2nd ed. Hanover: Quintessence Publishing Co, 2010.

6. Shaik M, Rao N, Kumar N, Prasanthi G. Comparison of rigid and semirigid fixation for advancement genioplasty. Journal of maxillofacial and oral surgery 2013; 12(3): 260-5.

7. Erkmen E, Şimşek B, Yücel E, Kurt A. Threedimensional finite element analysis used to compare methods of fixation after sagittal split ramus osteotomy: setback surgery-posterior loading. British Journal of Oral and Maxillofacial Surgery 2005; 43(2): 97-104.

8. Azevedo C, Hippert E. Failure analysis of surgical implants in Brazil. Engineering Failure Analysis 2002; 9(6): 621-33.

9. Azevedo C, Marques E. Three dimensional analysis of fracture, corrosion and wear surfaces. Engineering Failure Analysis 2010; 17(1): 286-300.

10.Azevedo C. Failure analysis of a commercially pure titanium plate for osteosynthesis. Engineering Failure Analysis 2003; 10(2): 153-64.

11. Magne P. Efficient 3D finite element analysis of dental restorative procedures using micro-CT data. Dental materials 2007; 23(5): 539-48.

12. Ramos, VF, Pinto L, Basting R. Force and deformation stresses in customized and non-customized plates during simulation of advancement genioplasty. Journal of Cranio-Maxillofacial Surgery 2017; 45(11): 1820-7.

13.Polido WD, Bell WH. Long-term osseous and soft tissue changes after large chin advancements. Journal of Cranio-Maxillofacial Surgery 1993; 21 (2): 54-9.

14.Shaughnessy S, Mobarak KA, Høgevold HE, Espeland L.Long-term skeletal and soft-tissue responses after advancement genioplasty. American journal of orthodontics and dentofacial orthopedics 2006; 130(1): 8-17.

15.Lee GT, Jung HD, Kim SY, Park HS, Jung YS. The stability following advancement genioplasty with biodegradable screw fixation. British Journal of Oral and Maxillofacial Surgery 2014; 52(4): 363-8.
16. Reyneke J, Johnston T, Van der Linden WJ. Screw osteosynthesis compared with wire osteosynthesis in advancement genioplasty: a retrospective study of skeletal stability. British Journal of Oral and Maxillofacial Surgery 1997; 35(5): 352-6.

17. Yurtyapan H, Ayrancı F. Ilerletme Genioplastisinde Kullanılan Farklı Vida Sistemlerinin Stabilite ve Stres Dağılımlarının Sonlu Elemanlar Analizi ile Karşıllaştııılması. Turkiye Klinikleri Dishekimliği Bilimleri Dergisi 2019; 25(2): 124-32

18. Hannam AG, Stavness I, Lloyd JE, Fels S. A dynamic model of jaw and hyoid biomechanics during chewing. Journal of Biomechanics 2008; 41(5): 1069-76.

19.Celebi N, Rohner EC, Gateno J, Noble PC, Ismaily SK, Teichgraeber JF, Xia JH. Development of a mandibular motion simulator for total joint replacement. Journal of Oral and Maxillofacial Surgery 2011; 69(1): 66-79.

20. Huang HL, Huang JS, Ko CC, Hsu JT, Chang $\mathrm{CH}$, Chen MYC. Effects of splinted prosthesis supported a wide implant or two implants: a three-dimensional finite element analysis. Clinical oral implants research 2005; 16(4): 466-72.

21. Voo L, Kumaresan S, Pintar FA, Yoganandan $\mathrm{N}$, Sances A. Finite-element models of the human head. Medical and Biological Engineering and Computing 1996; 34(5): 37581.

22. Coskunses FM, Kan B, Mutlu I, Cilasun U, Celik $\mathrm{T}$. Evaluation of prebent miniplates in fixation of Le Fort I advancement osteotomy with the finite element method. Journal of CranioMaxillofacial Surgery 2015; 43(8): 1505-10.

23. Kan B, Coskunses FM, Mutlu I, Ugur L, Meral DG. Effects of inter-implant distance and implant length on the response to frontal traumatic force of two anterior implants in an atrophic mandible: three-dimensional finite element analysis. International journal of oral and maxillofacial surgery 2015; 44(7): 908-13.

24.Al-Moraissi E, Al-Hendi E. Are bicortical screw and plate osteosynthesis techniques equal in providing skeletal stability with the bilateral sagittal split osteotomy when used for mandibular advancement surgery? A systematic review and meta-analysis. International journal of oral and maxillofacial surgery 2016; 45(10): 1195-200. 
25.Al-Moraissi E, Ellis E. Stability of bicortical screw versus plate fixation after mandibular setback with the bilateral sagittal split osteotomy: a systematic review and meta-analysis. International Journal of Oral and Maxillofacial Surgery 2016; 45(1): 1-7.

26. Choi BH, Min YS, Yi CK, Lee wy, Do K. A comparison of the stability of miniplate with bicortical screw fixation after sagittal split setback. Oral Surgery, Oral Medicine, Oral Pathology, Oral Radiology, and Endodontology 2000; 90(4): 416-9.

27. Chung IH, Chung KY, Lee EK, Ihm JA, Park CJ, Lim JS, Hwang KG. Postoperative stability after sagittal split ramus osteotomies for a mandibular setback with monocortical plate fixation or bicortical screw fixation. J Oral Maxillofac Surg 2008; 66(3): 446-52.

28. Anucul B, Waite PD, Lemons JE. In vitro strength analysis of sagittal split osteotomy fixation: noncompression monocortical plates versus bicortical position screws. Journal of oral and maxillofacial surgery 1992; 50(12): 1295-9.

29.Sugiura T, Horiuchi K, Sugimura M, Tsutsumi S. Evaluation of threshold stress for bone resorption around screws based on in vivo strain measurement of miniplate. J Musculoskelet Neuronal Interact 2000; 1(2): 165-70.

30. Ganesh VK, Ramakrishna K, Ghista DN. Biomechanics of bone-fracture fixation by stiffness-graded plates in comparison with stainless-steel plates. Biomed Eng Online 2005; 4: 46.

Yazışma Adresi:

Ahmet AKTI

Selçuk Üniversitesi Diş Hekimliği Fakültesi

Ağız, Diş ve Çene Cerrahisi AD

Konya, Türkiye

Tel : +90 3322231150

Faks : +903322231253

E Posta: dt.ahmetakti@gmail.com 